\title{
Right heart failure in acute respiratory distress syndrome: An unappreciated albeit a potential target for intervention in the management of the disease
}

\section{Abhishek Biswas}
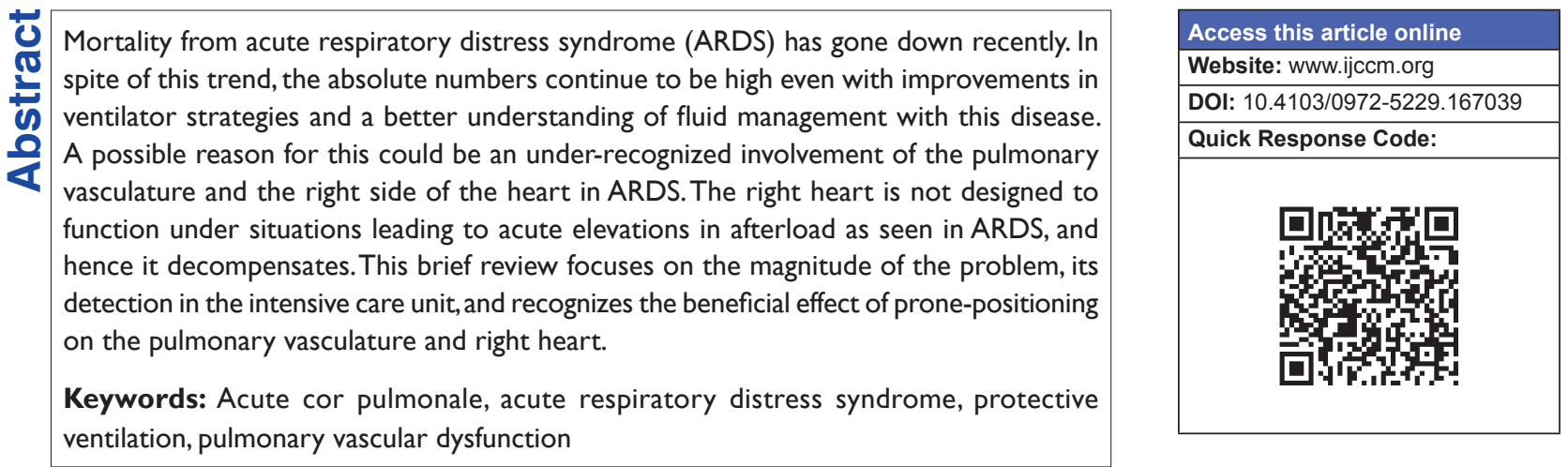

\section{Introduction}

Acute respiratory distress syndrome (ARDS) is a challenging disease where inappropriate treatment has the potential to propagate lung injury and causes additional harm as does the lack of appropriate treatment.

According to the most recent definition, ARDS has been classified into mild, moderate, and severe disease based on partial pressure of arterial $\mathrm{O}_{2}\left(\mathrm{PaO}_{2}\right)$ and the percentage of $\mathrm{O}_{2}$ in the inhaled gas $\left(\mathrm{FiO}_{2}\right)$ ratios $(\mathrm{P} / \mathrm{F}) \cdot{ }^{[1]}$ Mild ARDS is defined as $\mathrm{P} / \mathrm{F}$ ratio $>200 \mathrm{~mm} \mathrm{Hg}$, but $<300 \mathrm{~mm} \mathrm{Hg}$ with peak end-expiratory pressure (PEEP), or continuous positive airway pressure of $5 \mathrm{~cm} \mathrm{H}_{2} \mathrm{O}$. Moderate ARDS is defined as $\mathrm{P} / \mathrm{F}$ ratio $>100 \mathrm{~mm} \mathrm{Hg}$, but $<200 \mathrm{~mm} \mathrm{Hg}$ with PEEP of $5 \mathrm{~cm} \mathrm{H}_{2} \mathrm{O}$. A P/F ratio below $100 \mathrm{~mm} \mathrm{Hg}$ with

From:

Department of Pulmonary, Critical Care and Sleep Medicine, University of

Florida Shands Hospital, Gainesville, Florida 32610, USA

\section{Correspondence:}

Dr. Abhishek Biswas, Department of Pulmonary, Critical Care and Sleep Medicine, University of Florida Shands Hospital, 1600 SW Archer Avenue, Gainesville, Florida 32610, USA.

E-mail: abhibiswas78@gmail.com
PEEP of $5 \mathrm{~cm} \mathrm{H}_{2} \mathrm{O}$ is categorized as severe ARDS. The definition also requires that the condition has to occur within 1-week from a known clinical insult or from the onset of respiratory distress.

Substantial progress has been made in the understanding of the pathogenesis of the disease, and different treatment strategies have been proposed accordingly. However, most of them have been unsuccessful in reducing mortality. Only two strategies have shown consistent success in this regard. These are lung-protective ventilation and fluid-conservative therapy. ${ }^{[2-4]}$ More recently, two other strategies have been successful in reducing the mortality of ARDS. The first is a strategy

This is an open access article distributed under the terms of the Creative Commons Attribution-NonCommercial-ShareAlike 3.0 License, which allows others to remix, tweak, and build upon the work non-commercially, as long as the author is credited and the new creations are licensed under the identical terms.

For reprints contact: reprints@ medknow.com

How to cite this article: Biswas A. Right heart failure in acute respiratory distress syndrome: An unappreciated albeit a potential target for intervention in the management of the disease. Indian J Crit Care Med 2015;19:606-9. 
of prone-positioning patients with moderate to severe ARDS (defined by P/F < 150). The second strategy uses neuromuscular blockers while the patients are mechanically ventilated. The 2010 ARDS et Curarisation Systematique trial demonstrated the benefits of using Cisatracurium for $48 \mathrm{~h}$ in ARDS patients with $\mathrm{P} / \mathrm{F}$ ratios below 150. ${ }^{[5]}$ The 2013 Proning Severe ARDS Patients trial prone-positioned ARDS patients with moderate to severe ARDS and demonstrated its beneficial effects on 28- and 90-day mortality. ${ }^{[6]}$ There are multiple explanations as to why prone-positioning improves mortality. We now know that it is the reduction in ventilator-induced lung injury and not the improvement in hypoxemia that saved lives. ${ }^{[7]}$ The use of inhaled pulmonary vasodilators and extracorporeal membrane oxygenation has been applied to treat severe ARDS, but their use can only be justified in the most severe hypoxemic patients who are refractory to usual management strategies. ${ }^{[8]}$

In spite of these advances, mortality continues to be high all over the world. Have these advancements been able to make a major impact on the absolute mortality figures? Unfortunately, the answer is no. The incidence and overall mortality of ARDS have not changed substantially over the last 10 to 15 years, and the current mortality of adult ARDS is still greater than $40 \% .{ }^{[9-11]}$ Does this indicate that there is an elusive aspect of ARDS management that has been ignored? There are multiple possible answers, but none emerges a clear winner.

One of the promising theories that have been proposed as an explanation for the above-mentioned phenomenon is based on the finding that a significant number of patients with ARDS have acute cor pulmonale (ACP). ACP has been associated with poor outcomes in other clinical situations, one of which is pulmonary embolism, and similar outcomes would not be entirely unexpected in ARDS. Unfortunately, very little has been done about it. It is high time that we recognized the occurrence of pulmonary vascular dysfunction and ACP in ARDS patients and the detrimental impact on outcomes. It is difficult to diagnose pulmonary vascular dysfunction without taking recourse to use pulmonary artery catheters (PACs), which fortunately is not the standard of care in most Intensive Care Units worldwide. However, right ventricular (RV) pressure overload and ACP are quantifiable without the use of PAC. Thus, most recent studies have used the echocardiographic measure of RV pressure overload to detect pulmonary vascular dysfunction.

$\mathrm{ACP}$ is identified on transesophageal echocardiography by a combination of RV enlargement with septal dyskinesia. ${ }^{[12]} \mathrm{RV}$ dilatation is defined by an RV end diastolic area (RVEDA)/left ventricular end diastolic area (LVEDA with both measured at end diastole) ratio of 0.6 .

\section{Incidence of Acute Cor Pulmonale in Acute Respiratory Distress Syndrome}

Multiple studies have shown that the incidence of $\mathrm{ACP}$ has decreased as we have improved our ventilator management strategies. The incidence has varied between $25 \%$ and $50 \%$ in various studies. ${ }^{[12-19]}$ The use of PAC to quantify transpulmonary gradient as a marker of pulmonary vascular dysfunction in ARDS has been studied retrospectively from the database of the Fluid and Catheter Treatment Trial Study by Bull et al. ${ }^{[20]}$ They documented a $>70 \%$ incidence of pulmonary vascular dysfunction among those with acute lung injury. This study also demonstrated that elevated transpulmonary gradients were independently associated with poor outcomes. Hence, now we know that pulmonary dysfunction is common and occurs in the most severe end of the spectrum of this disease. It can lead to RV dysfunction and ACP.

\section{Does Acute Cor Pulmonale Impact Mortality in Acute Respiratory Distress Syndrome?}

ACP had traditionally been considered to be just a marker of severity and was thought to have no direct impact on prognosis. But recent studies have shown that it is associated with significant increase in resting heart rate, a decrease in systemic blood pressure and a greater need for hemodynamic support. It was found to be independently associated with 28-day mortality and in-hospital mortality. Other associations included one with elevated lactate levels and a more frequent requirement for prone-positioning and Nitric Oxide rescue therapy. ${ }^{[18]}$

\section{How Do Patients with Acute Respiratory Distress Syndrome Develop Acute Cor Pulmonale?}

The following mechanisms have been suggested to play a crucial role in the development of ACP in ARDS:

- ARDS affects not only alveoli but also the pulmonary circulation. This is due to inflammation, vasoconstriction, edema, thrombi, and vascular remodeling leading to increased pulmonary vascular resistance. ${ }^{[21]}$

- The increase in pulmonary artery pressure may be ascribed to unadapted positive pressure ventilation, inducing a deleterious competition between the 
distending pressure of alveoli and the flow into pulmonary capillaries. Thus, it has been observed that with a PEEP $>10 \mathrm{~cm} \mathrm{H}_{2} \mathrm{O}$, the pulmonary artery occlusion pressure (which under normal circumstances is equal to left ventricular end diastolic pressure [LVEDP]) is higher than the LVEDP. To understand this concept, we will have to review the relationship between lung stretch and pulmonary vascular resistance. This is clearly explained by the Whittenberger curve [Figure 1]. ${ }^{[22-24]}$ This describes a biphasic response in pulmonary vascular resistance as we inflate the alveoli from complete collapse to over-inflation. The vascular resistance is least in a segment of the curve where the normal lungs function. Both over-distension of the alveoli and atelectasis have the same effect on vascular resistance

- Permissive hypercapnia may also have a role to play by causing hypercapnic vasoconstriction in ARDS.

\section{What are the Factors that Impact Acute Cor Pulmonale?}

Boissier et al. published a study of 226 moderate to severe ARDS and identified that infection as a cause of ARDS and elevated driving pressures $(\Delta \mathrm{P})$ were independently associated with the development of ACP on multivariate analysis. ${ }^{[18]}$ In fact, driving pressures have very recently been described as the best predictor of survival in patients with ARDS. The authors defined driving pressure as $\Delta \mathrm{P}=\mathrm{V}_{\mathrm{T}} / \mathrm{C}_{\mathrm{RS}}$ where $\mathrm{V}_{\mathrm{T}}$ is the tidal volume and $\mathrm{C}_{\mathrm{RS}}$ is the compliance of the respiratory system. ${ }^{[25]}$ Other studies have indicated hypercapnia, $\mathrm{PaCO}_{2}>60$ as an independent risk factor for development of ACP. ${ }^{[13,19]}$ Higher plateau pressures, particularly above $35 \mathrm{~mm}$ of $\mathrm{Hg}$, have also been noted to be associated with ACP. ${ }^{[13]}$

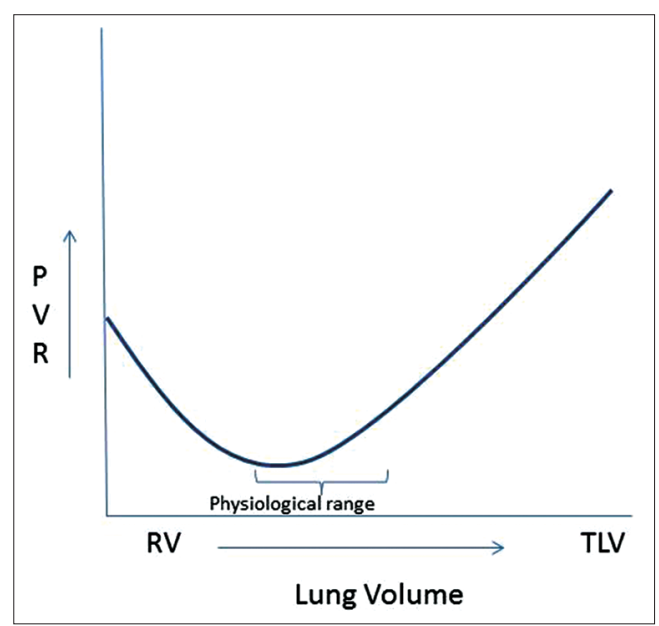

Figure I: U-shaped relationship between pulmonary vascular resistance and lung stress with lowest pulmonary vascular resistance at function residual capacity. Resistance increases as there is over-distension of alveoli or atelectasis. This was described by Whittenberger et al.

\section{What Can We Do to Reduce Right Sided Pressure in Acute Respiratory Distress Syndrome?}

Based on the above discussion, any maneuver that reduces $\mathrm{PEEP}, \mathrm{PaCO}_{2}$, and driving pressure keeping plateau pressures as low as possible should theoretically help to achieve that goal. In practice, these concepts are often difficult to implement. In order to optimize oxygenation, intensivists will often accept a higher $\mathrm{PaCO}_{2}$. Apart from lung-protective ventilation, the only other ventilation strategy that has shown significant reproducible improvements in oxygenation and mortality from ARDS is prone-positioning. ${ }^{[6]}$ Prone-positioning by itself also gives us the opportunity to reduce the need for higher PEEP, allows us to target a lower plateau pressure and has been shown to reduce RV dilation/ACP. ${ }^{[14]}$ It has been demonstrated that prone-positioning in severe ARDS is associated with statistically significant reductions in $\mathrm{PaCO}_{2}$ and plateau pressures, and improvement in $\mathrm{P} / \mathrm{F}$ ratio. Interestingly, the ratio between the RVEDA and LVEDA was significantly reduced in only those who have both severe ARDS and ACP. Similar improvement in RV dimensions also occurred in those without $\mathrm{ACP}$ on prone-positioning, but the change was not statistically significant. Significant improvement in left ventricular ejection fraction with prone-positioning was also seen in the group of patients that had ACP. ${ }^{[14]}$

\section{Conclusion}

Even though the occurrence of ACP has diminished in the modern era of low-tidal volume ventilation, it is still seen in a significant proportion of patients with severe ARDS. The good news is that significant improvement of RV function may be achieved in all patients with ACP in severe ARDS who undergo prone-positioning. Early identification of right heart pressure overload and ACP is crucial, particularly in view of data that indicate that $\mathrm{ACP}$ impacts mortality in ARDS. Fortunately, we do not need PACs to monitor pulmonary artery pressures. Instead, echocardiography can help us to identify patients with ACP. Transesophageal echocardiography is a sensitive modality used to evaluate the right ventricle and septal dyskinesia. Thus, based on recent studies, the French Society of Intensive Care Medicine has recognized the need for monitoring the right ventricle in patients with ARDS. ${ }^{[26]}$

The crucial question that still needs to be answered is whether we should consider prone-positioning patients with $\mathrm{ACP}$, who do not have a $\mathrm{P} / \mathrm{F}<150 \mathrm{~mm}$ of $\mathrm{Hg}$ ? It is also necessary to consider whether it is time to implement a stricter plateau pressure limits in all patients with ARDS irrespective of whether they have ACP or not. 
Finally, we need to consider the need to implement a "right ventricle-protective strategy" for ventilation. This involves a stricter control of plateau pressures (preferably below $27 \mathrm{~mm}$ of $\mathrm{Hg}$ ), keeping $\mathrm{PaCO}_{2}$ below $60 \mathrm{~mm}$ of $\mathrm{Hg}$ and restricting driving pressures to as low as possible. ${ }^{[27,28]}$ Prone-positioning carries the greatest potential of transforming this concept to life.

Surely, a lot of research is still needed to determine the exact pathways by which ARDS affects the pulmonary vasculature, and subsequently worsens RV function. Assessment of pulmonary vascular resistance and right ventricular dysfunction in severe ARDS may open a new frontier in our fight against ARDS.

\section{Financial support and sponsorship \\ Nil.}

\section{Conflicts of interest}

There are no conflicts of interest.

\section{References}

1. ARDS Definition Task Force, Ranieri VM, Rubenfeld GD, Thompson BT, Ferguson ND, Caldwell E, et al. Acute respiratory distress syndrome: The Berlin definition. JAMA 2012;307:2526-33.

2. Tidal L. Ventilation with lower tidal volumes as compared with traditional tidal volumes for acute lung injury and the acute respiratory distress syndrome. N Engl J Med 2000;342:1301-8.

3. Schuller D, Schuster DP. Fluid-management strategies in acute lung injury. N Engl J Med 2006;355:1175.

4. Matthay MA, Ware LB, Zimmerman GA. The acute respiratory distress syndrome. J Clin Invest 2012;122:2731-40.

5. Papazian L, Forel JM, Gacouin A, Penot-Ragon C, Perrin G, Loundou A, et al. Neuromuscular blockers in early acute respiratory distress syndrome. N Engl J Med 2010;363:1107-16.

6. Gattinoni L, Tognoni G, Pesenti A, Taccone P, Mascheroni D, Labarta V, et al. Effect of prone positioning on the survival of patients with acute respiratory failure. N Engl J Med 2001;345:568-73.

7. Albert RK, Keniston A, Baboi L, Ayzac L, Guérin C, Proseva Investigators. Prone position-induced improvement in gas exchange does not predict improved survival in the acute respiratory distress syndrome. Am J Respir Crit Care Med 2014;189:494-6.

8. Abrams D, Brodie D. Management options for refractory ARDS: A concise clinical review. PulmCCM J 2015. Edition 1. [Last modified on 2015 Jan 31].

9. Villar J, Sulemanji D, Kacmarek RM. The acute respiratory distress syndrome: Incidence and mortality, has it changed? Curr Opin Crit Care 2014;20:3-9.

10. Zambon M, Vincent JL. Mortality rates for patients with acute lung injury/ARDS have decreased over time. Chest 2008;133:1120-7.

11. Phua J, Badia JR, Adhikari NK, Friedrich JO, Fowler RA,
Singh JM, et al. Has mortality from acute respiratory distress syndrome decreased over time?: A systematic review. Am J Respir Crit Care Med 2009;179:220-7.

12. Vieillard-Baron A, Schmitt JM, Augarde R, Fellahi JL, Prin S, Page $\mathrm{B}$, et al. Acute cor pulmonale in acute respiratory distress syndrome submitted to protective ventilation: Incidence, clinical implications, and prognosis. Crit Care Med 2001;29:1551-5.

13. Vieillard-Baron A, Page B, Augarde R, Prin S, Qanadli S, Beauchet A, et al. Acute cor pulmonale in massive pulmonary embolism: Incidence, echocardiographic pattern, clinical implications and recovery rate. Intensive Care Med 2001;27:1481-6.

14. Vieillard-Baron A, Charron C, Caille V, Belliard G, Page B, Jardin F. Prone positioning unloads the right ventricle in severe ARDS. Chest 2007;132:1440-6.

15. Fougères E, Teboul JL, Richard C, Osman D, Chemla D, Monnet X. Hemodynamic impact of a positive end-expiratory pressure setting in acute respiratory distress syndrome: Importance of the volume status. Crit Care Med 2010;38:802-7.

16. Brown SM, Pittman J, Miller Iii RR, Horton KD, Markewitz B, Hirshberg E, et al. Right and left heart failure in severe H1N1 influenza A infection. Eur Respir J 2011;37:112-8.

17. Mekontso Dessap A, Proost O, Boissier F, Louis B, Roche Campo F, Brochard L. Transesophageal echocardiography in prone position during severe acute respiratory distress syndrome. Intensive Care Med 2011;37:430-4

18. Boissier F, Katsahian S, Razazi K, Thille AW, Roche-Campo F, Leon R, et al. Prevalence and prognosis of cor pulmonale during protective ventilation for acute respiratory distress syndrome. Intensive Care Med 2013:39:1725-33.

19. Lhéritier G, Legras A, Caille A, Lherm T, Mathonnet A, Frat JP, et al. Prevalence and prognostic value of acute cor pulmonale and patent foramen ovale in ventilated patients with early acute respiratory distress syndrome: A multicenter study. Intensive Care Med 2013;39:1734-42.

20. Bull TM, Clark B, McFann K, Moss M, National Institutes of Health/ National Heart, Lung, and Blood. Pulmonary vascular dysfunction is associated with poor outcomes in patients with acute lung injury. Am J Respir Crit Care Med 2010;182:1123-8.

21. Zapol WM, Snider MT. Pulmonary hypertension in severe acute respiratory failure. N Engl J Med 1977;296:476-80.

22. Whittenberger JL, Megregor M, Berglund E, Borst HG. Influence of state of inflation of the lung on pulmonary vascular resistance. J Appl Physiol 1960;15:878-82

23. Repessé X, Charron C, Vieillard-Baron A. Right ventricular failure in acute lung injury and acute respiratory distress syndrome. Minerva Anestesiol 2012;78:941-8.

24. Niden AH. The acute effects of atelectasis on the pulmonary circulation. J Clin Invest 1964;43:810-24.

25. Amato MB, Meade MO, Slutsky AS, Brochard L, Costa EL, Schoenfeld DA, et al. Driving pressure and survival in the acute respiratory distress syndrome. N Engl J Med 2015;372:747-55.

26. Richard J, Girault C, Leteurtre S, Leclere F, Group TS. Ventilatory management of acute respiratory distress syndrome (ARDS) in adult patients and children (excluding neonates). Réanimation 2005; $14: 323-32$

27. Vieillard-Baron A, Price LC, Matthay MA. Acute cor pulmonale in ARDS. Intensive Care Med 2013;39:1836-8.

28. Repessé X, Charron C, Vieillard-Baron A. Acute cor pulmonale in ARDS: Rationale for protecting the right ventricle. Chest 2015;147:259-65. 